\title{
Quality of Life Among Elderly After Retirement at Assuit City
}

\author{
Nawal Gad Mohamed ${ }^{1}$, Soad Abd El-Hamed Sharkawy ${ }^{2}$ \& Nermeen Mahmoud Abd El-Aziz ${ }^{3 .}$ \\ 1. Nursing Specialist of Technical Health Institute, Assuit City, Egypt. \\ 2. Professor of Community Health Nursing, Faculty of Nursing, Assiut University, Egypt. \\ 3. Assistant Professor of Gerontological Nursing, Faculty of Nursing, Assiut University, Egypt.
}

\begin{abstract}
Background: Retirement is one of the most important events in a series of interconnected critical situations interfering with the quality of life of the elderly. Study aim: To assess the quality of life among the elderly after retirement at Assiut City. Design: A Cross-sectional Descriptive Study Design was utilized. Sample: The total sample size was 300 retired elderly employees attending the Geriatric club of Legitimacy Assembly and the Geriatric club of Islamic Cultural for Center. Study Tools: An interview questionnaire sheet that included two tools was used: Tool (1): The Socioeconomic Scale developed by (Abd eltawab scale 2012). Tool (2): The Older People's Quality of life Questionnaire (OPQOL). Results: It was found that $44.3 \%$ of the studied retired elderly aging between 60 - 65 years. The mean age \pm S.D was $65.53 \pm 3.57$. Regarding the gender difference of the studied sample, $62.3 \%$ of them were males. Regarding the total score of the Quality of life among the studied retired elderly, it was found that $34.7 \%$ of the studied sample had a low score of quality of life, while $38.7 \%$ of them had a moderate score and $26.6 \%$ of them had a high score. Conclusion: There is a statistically significant (positivenegative) correlation between age, sex, income of studied elderly and their total QOL. Recommendations: More studies should be implemented to assess public health awareness of the retired elderly for improving QOL and health education programs for the elderly at the age of retirement through workshops.
\end{abstract}

\section{Keywords: Quality of Life, Elderly \& Retirement.}

\section{Introduction}

Globally, the population is ageing rapidly. Between 2015 and 2050, the proportion of the world's population over 60 years would nearly double from $12 \%$ to $22 \%$. Between 2015 and 2030, the number of people in the world aging 60 years or over would be projected to a growth rate of $56 \%$, from 901 million to 1.4 billion, and by 2050 , the global population of elderly persons would be projected to more than twice its size in 2015, reaching nearly 2.1 billion (WHO, 2018).

In Egypt, there is a gradual increase in the absolute and relative number of elder people over the last few decades. Elderly people defined as 60 years of age or more constituted that the total population of Egyptian people is 94.8 million, elderly people (60 years and more) represents 7\% of the total population in Egypt and is expected to reach $12 \%$ by 2030 (Central agency for public mobilization \& statistics, 2019).

Retirement is withdrawing from one's position or occupation or from active working life. In real life, the definition of retirement is not so simple. It is a very complex process. Retirement is one of the most important events for elder workers. Retirement has an impact on the individuals as well as on their sociocultural environment. Retirement has an impact on how they spend their time, income, social interaction and, most likely, on their physical and mental health, self-esteem and life satisfaction (Hank \& Erlinghagen, 2015).

Retirement, for some people, is positively assimilated, and leads to a reorganization of life; while for others, it is significantly damaging and affecting their psychic structure. These effects can appear throughout feelings and psychological symptoms like anxiety, depression, irritability, and general dissatisfaction resulting in a reduction in the quality of life (Carstensen, et al., 2018).

Retirement repercussions related to emotional and subjective life also can interfere with eating patterns. The loneliness of the elderly population may cause them to lose interest in eating, before retirement, eating moments were shared with working colleagues, and the time and location of meals were consistent and predetermined. Retirement can be seen as an event wrapped by a series of interconnected critical situations interfering with the quality of life for the elderly (Hank \& Erlinghagen, 2015).

The term quality of life is a subjective perception of well-being and wholeness. However, the quality of life; perceived by a person or group, reaches beyond physical health, necessitating a broad and complex analysis considering factors such as socio-economic level, emotional state, social interaction, intellectual activity, cultural values, lifestyle, employment and/or daily activities, satisfaction, and the living 
environment (Arslantas, 2019).

The gerontological nursing helps aging persons understand and face the common changes associated with advanced age. Encourages factors that promote optimum function (such as, diet, paced activity, physical examination, etc.). Offers assistance with attention to preserving as much of the individual's independence and dignity as possible. Can provide focused health screening, counseling, crisis intervention, and comprehensive care to this population. Provides essential educational services to older clients, their families, other nursing and health care professionals involved in their career (Galarneau, et al., 2016).

\section{Significance of the study}

Quality of life is widely accepted as an indicator of successful ageing, and it is monitored as a means of measuring the effectiveness of social policies, welfare programs, and health care. For this reason, quality of life is increasingly assessed in population surveys of older people, and findings have been encouraging (Bowling, et al., 2017).

Retirement is accompanied by many basic life changes: time availability, income, social status feeling lonely and so on. Life style changes are likely to affect the retirees' state of health. The incidence of retirement in Assuit City during the year 2016 is 865 retired people (Infurna, et al., 2016). So this study was carried out to assess the quality of life for retirement elderly. The researchers assessed the elderly quality of life.

\section{Aim of the study}

- To assess the quality of life among the retired elderly attending the Islamic culture club and legitimacy Assembly.

- To assess the effect of socioeconomic status on the retired elderly.

\section{Research Questions}

- What is the quality of life for the elderly after retirement?

- Does the socioeconomic status have an affect on the quality of life?

\section{Subjects \& Methods}

Research design: The Cross-sectional Descriptive Design was utilized in this study.

Settings: The study was conducted in two geriatric clubs in the City of Assiut ( the Geriatric club of Legitimacy Assembly and the Geriatric club of the Islamic Cultural Center) which provides social, recreational and health services for the elderly.

\section{Sampling}

Type of sample: total coverage sample which was used in the study included all of the elderly attending the previously mentioned settings aging 60 years and more.

Total number of the study sample was (300) retired elderly persons. Divided into two (110) elderly who attending to Geriatric club of Legitimacy Assembly and (190) retired elderly who attending to Geriatric club of Islamic Cultural Center.

Tools of the study: The Interview questionnaire which was use included two tools;

Tool (1)

The Socioeconomic Scale, which was developed by Abd eltawab, includes personal characteristics such as (name, age, level of education, occupation, family income and etc....) (Abd eltawab scale 2012).

Scoring system: The socioeconomic status was assessed by using a scale that comprised seven domains with a maximum score of 84 and a higher score indicating better socioeconomic status. The Socioeconomic scores were classified into 4 levels, scores $<42$ (very low), $42<63$ (low), $63<71.4$ (moderate) and 71.4 -84 (high social level).

Tool (2): Older People's Quality of life Questionnaire (OPQOL)

The OPQOL was developed by (Bowling \& Stenner, 2010) and was tested by the ESRC and cross-research council funding. It is a 35-item QOL measure, which represents: overall life (4 items), health (4 items), social relationships (5 items) independence, control over life, freedom (4 items) home and neighborhood (4 items), psychological and emotional wellbeing (4 items), financial circumstances (4 items), leisure and activity (6 items). It has 5-point Likert scale measures from strongly agree, agree, neither agree or disagree, disagree and strongly disagree.

Scoring system of Older People's Quality of Life Questionnaire: OPQOL items coded 1-5 (Strongly agree, agree, neither agree or disagree, disagree and strongly disagree) scoring. The scores of the items were summed up and the total was divided by the number of the items, giving a mean score for the quality of life. These scores were converted into a percent score. The scoring system, used in QOL scale, had three levels (low, moderate, and high). The total score was 175 point, who obtained less than $50 \%$ were considered low QOL, who obtained $50 \leq 75 \%$ were considered moderate QOL, and who scored more than $75 \%$ were considered high on QOL (Bowling \& Stenner, 2010).

\section{Methods}

Administrative phase

A written permission was obtained from the Dean of the Faculty of Nursing, Assuit University to Islamic culture club and society legitimacy in Assuit city this letter included a brief explanation of the objective of the study and a permission to carry out the study. 


\section{Pilot study}

The pilot study was carried out on $10 \%$ of the studied elderly. The elderly who participated in the pilot study were taken from the study sample. The aim of the pilot study is to test the feasibility, clarity and to estimate the required time to fill in the questionnaire. According to the result of pilot study, the necessary modification was done to avoid the ambiguity of the questionnaire. Validity and reliability of the tools

The tools were investigated by ( 5 judges), from the community of health nursing and gerontological nursing staff in Assiut University to survey and assess the sheets and other things to secure the reliability of the sheet. Changes were furnished by the headings of the judge's council. Reliability was analyzed by Cronbach's alpha the value was 0.900 .

\section{Field work}

The researchers met the elderly, explained to them the purpose of the study, and asked for their voluntary participation. The researchers started a face to face individual interview with the elderly, completed the sheet for all People and wrote exactly the answers that the elderly had given. The Data was collected in a period of nine-month time span starting from the first of March 2018 to the end of December 2018, through three days weekly. The approximate time spent for the filling in of the sheets was around 20 - 30 minutes. Two days in the Islamic culture club and one day in the Society Legitimacy in Assiut city.

\section{Ethical considerations}

- The research proposal was approved by an ethical research committee in the Faculty of Nursing, Assiut University.

- There was no risk against the study courses during the application of the research.

- The study was pursuant to the common ethical principles in clinical research.

- Oral consent was obtained from the elderly who were willing to participate in the study after explaining its nature and purpose.

- Confidentiality and anonymity were assured.

- Study subjects had the right to refuse to participate or withdraw from the study without any reason and at any time.

\section{Statistical analysis}

Data entry and data analysis were done using SPSS version 22 (Statistical Package for Social Science). Data were presented as numbers, percentages, mean scores, and standard deviations. An independent sample t-test was used to compare the quantitative variables between two groups and ANOVA test was done for more than two groups. Pearson correlation was done to measure correlation between quantitative variables. P-value was considered to be statistically significant when $\mathrm{P}<0.05$. 


\section{Results}

Table (1): Distribution of the studied retired elderly according to their socio-demographic characteristics.

\begin{tabular}{|c|c|c|}
\hline Variable & No. $(n=300)$ & $\%$ \\
\hline \multicolumn{3}{|l|}{ Age: (years) } \\
\hline $60-$ & 133 & 44.3 \\
\hline $65-$ & 128 & 42.7 \\
\hline$\leq 70$ & 39 & 13.0 \\
\hline $\begin{array}{l}\text { Mean } \pm \text { SD } \\
(\text { Range })\end{array}$ & \multicolumn{2}{|c|}{$\begin{array}{c}65.53 \pm 3.57 \\
(60.0-79.0)\end{array}$} \\
\hline \multicolumn{3}{|l|}{ Gender: } \\
\hline Male & 113 & 37.7 \\
\hline Female & 187 & 62.3 \\
\hline \multicolumn{3}{|l|}{ Level of education: } \\
\hline Illiterate & 5 & 1.7 \\
\hline Read \& write & 9 & 3.0 \\
\hline Primary & 20 & 6.7 \\
\hline Preparatory & 21 & 7.0 \\
\hline Secondary & 143 & 47.7 \\
\hline University & 102 & 34.0 \\
\hline \multicolumn{3}{|l|}{ Family income: } \\
\hline $300-$ & 3 & 1.0 \\
\hline $600-$ & 18 & 6.0 \\
\hline $1000-$ & 224 & 74.7 \\
\hline $1800-<4000 \mathrm{LE}$ & 55 & 18.3 \\
\hline \multicolumn{3}{|l|}{ Residence: } \\
\hline Rural & 84 & 28.0 \\
\hline Urban & 216 & 72.0 \\
\hline \multicolumn{3}{|l|}{ Living: } \\
\hline Alone & 24 & 8.0 \\
\hline With family & 276 & 92.0 \\
\hline \multicolumn{3}{|c|}{ Persons responsible for providing care: } \\
\hline Himself/ Herself & 40 & 13.3 \\
\hline Husband /wife & 116 & 38.7 \\
\hline Sons/ daughters & 139 & 46.3 \\
\hline Others & 5 & 1.7 \\
\hline \multicolumn{3}{|l|}{ No. of family members: } \\
\hline$<5$ & 138 & 46.0 \\
\hline $5-6$ & 80 & 26.7 \\
\hline 7 or more & 82 & 27.3 \\
\hline $\begin{array}{l}\text { Mean } \pm \text { SD } \\
\text { (Range) }\end{array}$ & \multicolumn{2}{|c|}{$\begin{array}{c}5.40 \pm 2.08 \\
(2-12)\end{array}$} \\
\hline \multicolumn{3}{|l|}{ Social class: } \\
\hline Low & 71 & 23.7 \\
\hline Middle & 173 & 57.7 \\
\hline High & 56 & 18.6 \\
\hline
\end{tabular}




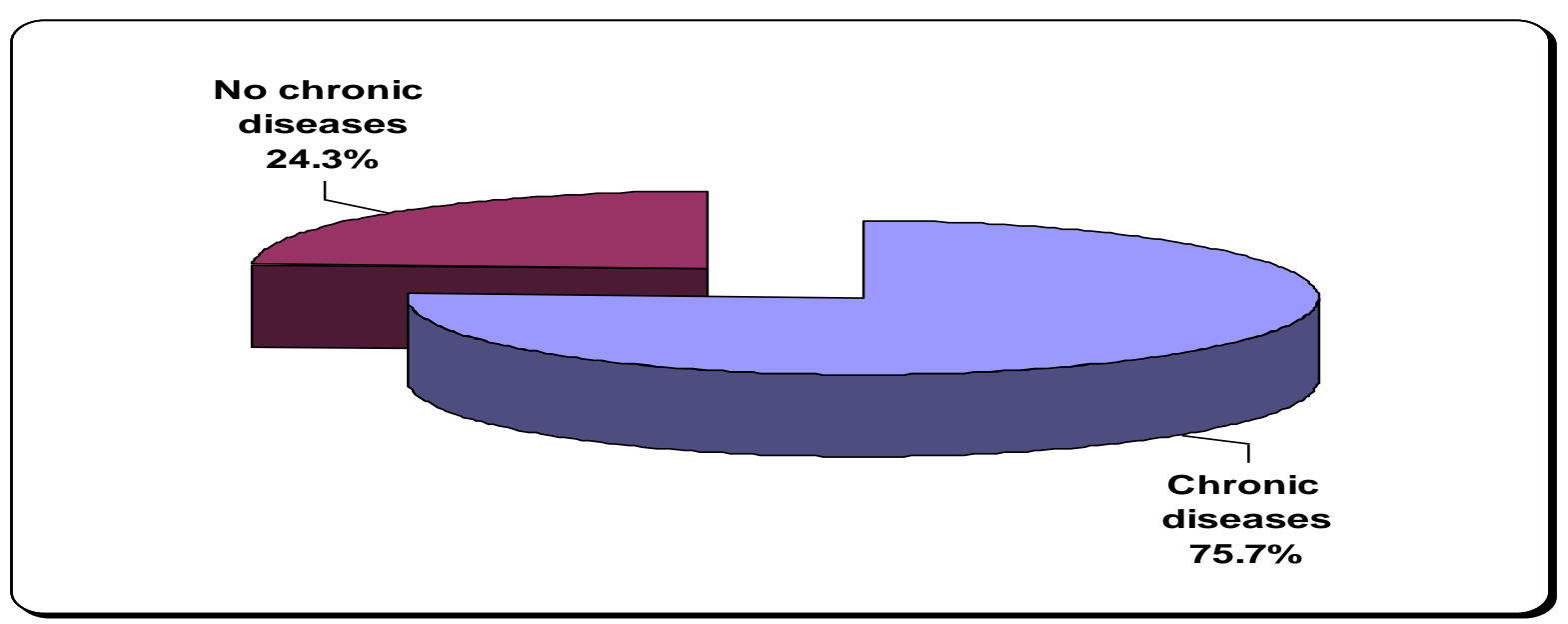

Figure (1): Percentage distribution of chronic diseases among retired elderly.

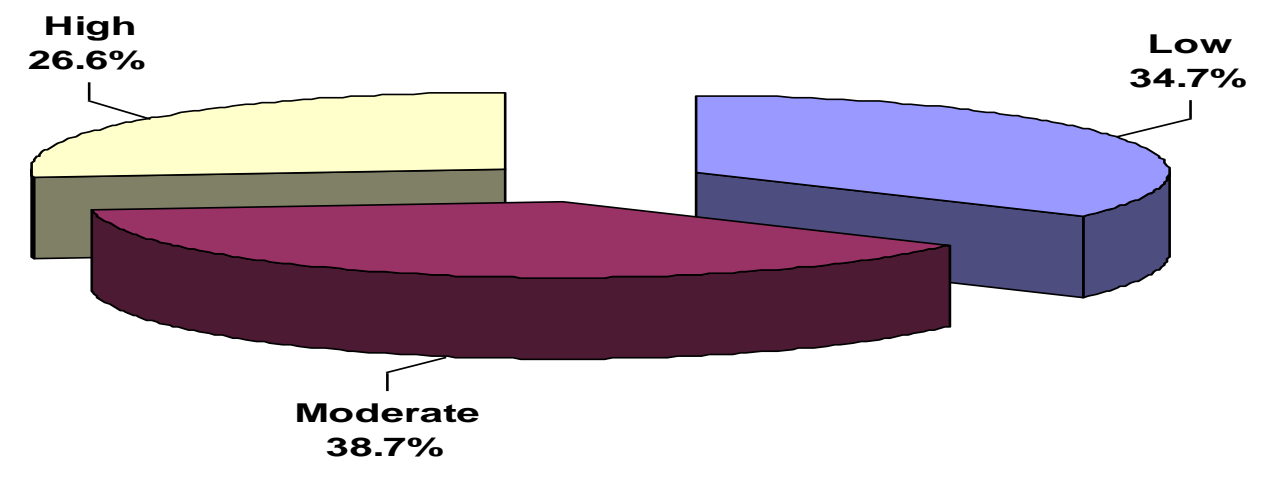

Figure (2): distribution of total quality of life domains' scores among the retired elderly.

Table (2): Relationship between QOL domains of studied retired elderly and their age

\begin{tabular}{|l|c|c|c|c|}
\hline \multirow{2}{*}{\multicolumn{1}{|c|}{ Quality of life domain }} & \multicolumn{3}{c|}{ Age (years) } & \multirow{2}{*}{ P-value } \\
\cline { 2 - 4 } & $\mathbf{6 0}-<\mathbf{6 5}$ & $\mathbf{6 5}-<\mathbf{7 0}$ & $\geq \mathbf{7 0}$ & \\
\cline { 2 - 5 } & Mean \pm SD & Mean \pm SD & Mean \pm SD & \\
\hline Life overall & $14.09 \pm 1.84$ & $13.63 \pm 2.15$ & $12.51 \pm 2.29$ & $0.000^{*}$ \\
\hline Health & $12.81 \pm 2.13$ & $11.82 \pm 2.17$ & $11.08 \pm 2.53$ & $0.000^{*}$ \\
\hline Social relationships & $20.02 \pm 2.26$ & $19.88 \pm 1.84$ & $19.03 \pm 1.95$ & $0.004^{*}$ \\
\hline Independence, control over life, freedom & $12.92 \pm 1.63$ & $11.63 \pm 2.14$ & $12.95 \pm 1.54$ & $0.000^{*}$ \\
\hline Home and neighborhood & $17.00 \pm 1.25$ & $16.67 \pm 1.57$ & $15.90 \pm 1.52$ & $0.001^{*}$ \\
\hline Psychological and emotional well-being & $14.66 \pm 1.92$ & $13.50 \pm 2.07$ & $12.44 \pm 2.63$ & $0.000^{*}$ \\
\hline Financial circumstances & $11.32 \pm 1.89$ & $10.90 \pm 2.18$ & $11.33 \pm 2.43$ & 0.100 \\
\hline Leisure and activities & $24.11 \pm 2.09$ & $22.73 \pm 2.23$ & $22.44 \pm 2.35$ & $0.000^{*}$ \\
\hline Total QOL & $126.92 \pm 7.92$ & $120.76 \pm 9.32$ & $117.67 \pm 11.19$ & $0.000^{*}$ \\
\hline
\end{tabular}

*statistically significant differences 
Table (3): Relationship between QOL domains of studied elderly and their sex.

\begin{tabular}{|l|c|c|c|}
\hline \multirow{2}{*}{\multicolumn{1}{|c|}{ Quality of life domain }} & \multicolumn{2}{|c|}{ Sex } & \multirow{2}{*}{ P-value } \\
\cline { 2 - 3 } & Male & Female & \\
\cline { 2 - 3 } & Mean \pm SD & Mean \pm SD & \\
\hline Life overall & $13.24 \pm 2.17$ & $13.96 \pm 2.00$ & $0.000^{*}$ \\
\hline Health & $12.08 \pm 2.32$ & $12.21 \pm 2.26$ & 0.318 \\
\hline Social relationships & $19.21 \pm 1.89$ & $20.20 \pm 2.09$ & $0.000^{*}$ \\
\hline Independence, control over life, freedom & $12.80 \pm 1.42$ & $12.12 \pm 2.18$ & $0.003^{*}$ \\
\hline Home and neighborhood & $16.43 \pm 1.50$ & $16.89 \pm 1.43$ & $0.003^{*}$ \\
\hline Psychological and emotional well-being & $12.94 \pm 2.42$ & $14.44 \pm 1.88$ & $0.000^{*}$ \\
\hline Economic circumstances & $10.86 \pm 2.08$ & $11.31 \pm 2.09$ & 0.179 \\
\hline Leisure and activities & $22.91 \pm 2.10$ & $23.53 \pm 2.38$ & $0.004^{*}$ \\
\hline Total QOL & $120.47 \pm 10.31$ & $124.67 \pm 8.90$ & $0.000^{*}$ \\
\hline
\end{tabular}

*statistically significant differences

Table (4): Relationship between QOL domains of the studied retired elderly and their education.

\begin{tabular}{|c|c|c|c|c|c|}
\hline \multirow{3}{*}{ Quality of life domain } & \multicolumn{4}{|c|}{ Level of education } & \multirow{3}{*}{ P-value } \\
\hline & $\begin{array}{c}\text { Illiterate/ } \\
\text { Read \& write }\end{array}$ & $\begin{array}{c}\text { Basic } \\
\text { education }\end{array}$ & Secondary & University & \\
\hline & Mean \pm SD & Mean \pm SD & Mean \pm SD & Mean \pm SD & \\
\hline Life overall & $12.00 \pm 2.45$ & $12.95 \pm 1.88$ & $13.91 \pm 1.79$ & $13.91 \pm 2.36$ & $0.000^{*}$ \\
\hline Health & $12.21 \pm 2.86$ & $11.61 \pm 2.55$ & $11.93 \pm 2.22$ & $12.71 \pm 2.09$ & $0.022^{*}$ \\
\hline Social relationships & $17.86 \pm 3.06$ & $18.88 \pm 1.40$ & $20.09 \pm 1.78$ & $20.11 \pm 2.27$ & $0.000^{*}$ \\
\hline $\begin{array}{l}\text { Independence, control over life, } \\
\text { freedom }\end{array}$ & $12.64 \pm 1.74$ & $12.76 \pm 1.45$ & $11.82 \pm 1.91$ & 2.03 & $0.002^{*}$ \\
\hline Home and neighborhood & $16.00 \pm 1.84$ & $16.17 \pm 1.53$ & $16.97 \pm 1.34$ & $16.69 \pm 1.48$ & $0.008^{*}$ \\
\hline $\begin{array}{l}\text { Psychological and emotional well- } \\
\text { being }\end{array}$ & $13.79 \pm 2.69$ & $12.61 \pm 2.35$ & $13.83 \pm 1.94$ & $14.47 \pm 2.27$ & $0.000^{*}$ \\
\hline Financial circumstances & $11.50 \pm 2.77$ & $10.88 \pm 2.10$ & $10.73 \pm 1.77$ & $11.77 \pm 2.27$ & $0.001 *$ \\
\hline Leisure and activities & $22.86 \pm 2.82$ & $22.66 \pm 2.15$ & $22.90 \pm 2.18$ & $24.19 \pm 2.19$ & $0.000^{*}$ \\
\hline Total QOL & $118.86 \pm 13.40$ & $118.51 \pm 8.50$ & $122.16 \pm 7.78$ & $126.81 \pm 10.63$ & $0.000^{*}$ \\
\hline
\end{tabular}

*statistically significant differences

Table (5): Relationship between quality of life of the studied retired elderly and family income.

\begin{tabular}{|l|c|c|c|c|}
\hline \multirow{2}{*}{\multicolumn{1}{|c|}{ Quality of life domain }} & \multicolumn{3}{|c|}{ Family income } & \multirow{2}{*}{ P-value } \\
\cline { 2 - 5 } & $\mathbf{< 1 0 0 0}$ & $\mathbf{1 0 0 0}-<\mathbf{1 8 0 0}$ & $\mathbf{1 8 0 0}-<\mathbf{4 0 0 0}$ & \\
\cline { 2 - 5 } & Mean \pm SD & Mean \pm SD & Mean \pm SD & \\
\hline Life overall & $12.00 \pm 1.95$ & $13.76 \pm 2.02$ & $14.04 \pm 2.19$ & $0.000^{*}$ \\
\hline Health & $11.00 \pm 2.57$ & $12.17 \pm 2.18$ & $12.60 \pm 2.45$ & 0.061 \\
\hline Social relationships & $18.76 \pm 1.61$ & $20.07 \pm 2.04$ & $19.25 \pm 2.12$ & $0.000^{*}$ \\
\hline Independence, control over life, freedom & $12.10 \pm 1.51$ & $12.14 \pm 1.94$ & $13.45 \pm 1.81$ & $0.000^{*}$ \\
\hline Home and neighborhood & $15.52 \pm 1.72$ & $16.86 \pm 1.39$ & $16.60 \pm 1.50$ & $0.003^{*}$ \\
\hline Psychological and emotional well-being & $11.95 \pm 2.65$ & $14.01 \pm 2.10$ & $14.07 \pm 2.22$ & $0.002^{*}$ \\
\hline Economic circumstances & $10.52 \pm 1.78$ & $10.98 \pm 2.02$ & $12.02 \pm 2.30$ & $0.005^{*}$ \\
\hline Leisure and activities & $21.48 \pm 2.44$ & $23.44 \pm 2.17$ & $23.42 \pm 2.47$ & $0.003^{*}$ \\
\hline Total QOL & $113.33 \pm 9.77$ & $123.42 \pm 8.79$ & $125.45 \pm 10.90$ & $0.000^{*}$ \\
\hline
\end{tabular}

*statistically significant differences 
Table (6): Relationship between quality of life of the studied retired elderly and their social class.

\begin{tabular}{|l|c|c|c|c|}
\hline \multirow{2}{*}{\multicolumn{1}{c|}{ Quality of life domain }} & \multicolumn{3}{c|}{ Social class } & \multirow{2}{*}{ P-value } \\
\cline { 2 - 5 } & Low & Middle & High \\
\cline { 2 - 5 } & Mean \pm SD & Mean \pm SD & Mean \pm SD & \\
\hline Life overall & $12.76 \pm 2.00$ & $13.86 \pm 2.02$ & $14.34 \pm 2.07$ & $0.000^{*}$ \\
\hline Health & $11.39 \pm 2.36$ & $12.09 \pm 2.21$ & $13.38 \pm 1.89$ & $0.000^{*}$ \\
\hline Social Relationships & $18.73 \pm 1.95$ & $20.18 \pm 1.88$ & $20.12 \pm 2.32$ & $0.000^{*}$ \\
\hline Independence, Control over life, Freedom & $12.80 \pm 1.39$ & $11.88 \pm 1.98$ & $13.38 \pm 2.01$ & $0.000^{*}$ \\
\hline Home and Neighborhood & $16.18 \pm 1.38$ & $16.87 \pm 1.51$ & $16.93 \pm 1.31$ & $0.002^{*}$ \\
\hline Psychological and Emotional well-being & $12.44 \pm 2.10$ & $14.12 \pm 2.01$ & $14.96 \pm 2.11$ & $0.000^{*}$ \\
\hline Economic Circumstances & $10.68 \pm 2.01$ & $10.97 \pm 1.82$ & $12.27 \pm 2.58$ & $0.000^{*}$ \\
\hline Leisure and activities & $22.56 \pm 2.05$ & $23.22 \pm 2.30$ & $24.48 \pm 2.12$ & $0.000^{*}$ \\
\hline Total QOL & $117.55 \pm 8.61$ & $123.17 \pm 8.60$ & $129.86 \pm 9.76$ & $0.000^{*}$ \\
\hline
\end{tabular}

*statistically significant differences

Table (1): Demonstrates the distribution of the studied retired elderly regarding their sociodemographic characteristics. It was found that $44.3 \%$ of them aged between $(60-<65)$ years, while $13.0 \%$ of them aged 70 years and more. The mean age \pm S.D was $65.53 \pm 3.57$. Regarding the gender of the studied sample, $62.3 \%$ of them were males.

As regards educational status, it was observed that $47.7 \%$ of the studied sample had secondary education. As regards the social class, $57.7 \%$ of the studied sample came from a middle social class, while $18.6 \%$ of them were from a higher social class.

Figure (1): Shows that $75.7 \%$ of the studied retired elderly had chronic diseases, while $24.3 \%$ of them didn't have any chronic diseases.

Figure (2): Shows that $34.7 \%$ of the studied retired elderly had low a score of quality of life, while $38.7 \%$ of them had moderate score and $26.6 \%$ of them had high score.

Table (2): Shows that there were statistically significant differences between QOL domains and the age of the studied elderly except for the economic circumstances.

Table (3): Demonstrates that there were statistically significant differences between QOL domains and the gender of the studied elderly except for the economic circumstances and health domains.

Table (4): Illustrates that there were statistically significant differences between QOL domains and the level of education of the studied retired elderly.

Table (5): Illustrates the mean scores and standard deviations of the studied retired elderly regarding the quality of life. It was found that the mean scores of the leisure and activities domains $(23.30 \pm 2.29)$ were higher than the mean scores of social relationships, home and neighborhood and psychological and emotional well-being domains $(19.83 \pm 2.07,16.72 \pm$ 1.47 and $13.88 \pm 2.22$ ) respectively.
Table (5): Shows that there were statistically significant differences between QOL domains and the family income of the studied sample except for the health domain.

Table (6): Demonstrates that there were statistically significant differences between the QOL domains among the studied retired elderly and their social class.

\section{Discussion}

Old age, occurring in all living creatures without differentiation, is a continuous and universal process causing decreases in all functions. The elderly populations are increasing rapidly. These demographic changes are a direct result of the success of socio-economic developments that have led to a decline in mortality rates at all ages and a reduction in fertility. Ageing does not influence te quality of life (QOL) negatively, and a long period of good quality of life is possible. Therefore, the maintenance and improvement of the quality of life become important issues Naing et al., (2015).

As regards the socio-demographic characteristics of the studied retired elderly, the findings of the present study showed that less than half of them had age ranged between 60-65 years, although there were statistical significant differences between QOL domains and age of the studied elderly except financial circumstance this is supported by Naing et al., (2015), who study quality of life of the elderly people in Einme and found that less than half of the retired elderly were age 60-65 years. This finding agrees with Prior et al., (2012) who study the influence of chronic diseases on long-term change in physical health and found that less than half of the studied retired elderly had age between 60-69 years. Advanced age was found to affect significantly QOL of the elders. This is because advanced age is usually associated with limitations in self-care, decreased 
ability to perform basic tasks, and conversely lower the QOL level.

Regarding the sample gender, less than two thirds of them were females and more than one third of them were males and there were statistically significant differences between QOL domains and the gender of the studied retired elderly. This result was supported by Lima et al., (2009) who reported a significant impact of chronic diseases on the quality of life among the elderly in the state of São Paulo, Brazil and found that the females were slightly more affected than in the elderly males. However, this result was in disagreement with (Ibrahim, 2015), who reported an impact of ostomy of the quality of life for Egyptian cancer patients and explained the findings of this study in which the studied retired elderly men had a better QOL than the elderly women. In addition, it was observed that males complained of a more deterioration in their health status than females.

Concerning the place of residence, results revealed that less than one third of the study sample were living in the rural areas and more than two thirds of them were living in urban areas. This finding is in disagreement with the results of Mostafa, (2017) who studied this variable in hypertensive patients in the outpatient clinics of Sohag university hospital, stated that about three quarters of their studied sample lived in rural areas. On the other hand, the results of the present study agree with Arslantas et al., (2019) who hearing impairment among older adults; societal effects of hearing aid fitting among the moderately hearing impaired and reported that the prevalence of retired elderly is higher in urban areas than rural ones. Regarding their level of education, it was observed that the elderly illiterates, who can just read and write, have the lowest percentage in the study sample, while the highest percentage had secondary and university education. The current results are in disagreement with Mostafa, (2017) who reported that the majority of the studied sample was illiterate. On the other hand, the present study disagrees with Mahmoud, (2017) who examined the prevalence of hypertension among people more than 35 years old in Sohag city and reported that more than half of the studied sample were educated.

Alonson \& Ferrer (2014) reported that low level of education had been associated with poor QOL. It was mentioned in many literatures that higher education among the elders can properly identify and awareness of the important role of social support and realizing the need of increasing contact with mates, family members and friends in order to achieve a highly satisfying life. The study of Breeze et al., (2014) who found out an association of quality of life in old age in Britain with socio-economic position and supported this finding and added that low educational levels of the elderly can lead to an inadequate follow up pattern or even neglecting this important issue, which can affect; in a negative way, the health and accordingly the QOL of the elderly.

According to the social class level, it was noticed that the majority of the studied elderly were from middle social class levels and a clear correlation between QOL domains among the studied retired elderly and their social class. Also, supported with Sonntag (2013), their life situation- results of a qualitative study, added that poor quality of life and well-being is most common among elders suffering from low income, chronic illnesses, and lack of informal family support to assist in their care.

Regarding the income, it was noticed that $(74.7 \%)$ of the studied sample had an income of 1000- < 1800 pounds and $(18.3 \%)$ of them had income 1800- < 4000 pounds. Breeze et al., (2014) study supported the previous findings and added that poor income of the elders can lead to an inadequate follow up pattern or even neglecting this important issue, which can affect in a negative way of health and accordingly the QOL of elders. The quality of life score of those elders was higher in socio-economic status, thus greater than those who had a lower socioeconomic status.

This result was the same as that of Lima et al., (2009), who reported an impact of chronic diseases on the quality of life among the elderly in the state of São Paulo, Brazil and stated that the elderly with higher socio-economic status were more retirement paid and saving, permitting them to be more autonomous financially, thus enjoying a better quality of life. In addition, the socio-economic status is an important predicator of the quality of life; therefore, those elderly who have a lower socio-economic status need more attention.

As for chronic diseases, it was found that nearly three quarters of the studied retired elderly had chronic diseases. It may be related to lack of health awareness and follow up, or lack of availability or accessibility of health resources and increase of economy of drugs and investigation. This finding is inconsistent with the study conducted in Brazil by Melchiors et al., (2010) who studied the quality of life in hypertensive patients and concurrent validity of Minichal-Brazil, and found that $(31.4 \%)$ of the studied sample had chronic diseases.

\section{Conclusion}

Based on the results of the present study, it can be concluded that there is a statistically significant correlation between age, gender, income of the retired elderly and their total QOL. 


\section{Recommendations}

Based on the results of the present study, the researchers came up with the following recommendations

1- Encouraging educational programs and interventions to enhance the quality of life among the retired elderly.

2- Public health awareness of the retired elderly should be strengthened for improving the QOL.

3- Encouraging gerontological nurses' to help the retired elderly cope with stressors after retirement through workshops, conferences, and group discussion.

\section{References}

1- Abdel-Tawab A., (2012): a measure of the level of social-economic status of families and key appreciation. Professor of Education and Dean of the Faculty of Education - Assiut University.

2- Alonson J., Ferrer M., Gande C., \& Ware G., (2014): Health related quality of life associated with chronic condition in eight countries: results from the international quality of life assessment (IQOLA) project Qual life Res, PP. 13(2): 283-98.

3- Arslantas C., (2019): Hearing impairment among older adults; societal effects of hearing aid fitting among the moderately hearing impaired. PP.27 (5), 22-23.

4- Bowling, A., \& Stenner, P., (2010): Psychometric properties of the Older People's Quality of Life Questionnaire: which measure performs best with older people. Journal of Epidemiology and Community Health, $8,56$.

5- Bowling, A., Iliffe, S., Kessel, A., \& Higginson, I., (2017): Fear of dying in anethnically diverse society: cross-sectional studies of people aged 65+ in Britain.PostgraduateMedicalJournal,86:197202.

6- Breeze E., Jones D., \& Fletcher E., (2014): Association of Quality of Life in Old Age in Britain with Socioeconomic Position: Baseline Data from a Randomized Controlled Trail. J Epidemiol and Community Health; 58 (8): 667-73.

7- Carstensen, L., Turan, B., Scheibe, S., Ram, N., Ersner-Hershfield, H., Samanez-Larkin, G., \& Nesselroade, J., (2018): Emotional Experience Improves With Age: Evidence Based on Over 60 Years of Experience Sampling. Psychology \& Aging, 26 (1), 21-33.

8- Central agency for public mobilization statistic, (2019): The world Fact book. Field Listing-Age Structure-Updated 8 March 2019, from "http// Pupulications/fact book/docs/Profileguide.Html." www.capmas.gov.eg.
9- Galarneau, L., (2016): Gerontological Nursing Roles within the Southeastern Regional Geriatric Program, Kingston, Ontario, Canada. Lancet, 342, 1032-1036.

10-Hank, K., \& Erlinghagen, M., (2015): Dynamics of volunteering in older Europeans. The Gerontologist, 50(2), 170-178.

11-Ibrahim A., (2015): Impact of ostomy of the quality of life Egyptian cancer patient, the New Egyptian Journal of Medicine, Vol, 12(1).

12-Infurna, F., Gerstorf, D., \& Zarit, S., (2016): Substantial changes in mastery perceptions of dementia caregivers with the placement of a care recipient. The Journals of Gerontology Series B: Psychological Sciences and Social Sciences, 68(2), 202-214.

13-Lima M., Barros M., César C., Goldbaum M., Carandina L., \& Ciconelli R., (2009): Impact of chronic disease on quality of life among the elderly in the state of São Paulo, Brazil: a population-based study, Rev Panam Salud Publica, Public Health, Vol 25, No 4, P 314-21.

14-Mahmoud E., (2017): prevalence of hypertension among people more than 35 years old in Sohag city, Risk factors for hypertension, Sohag University. Faculty of Medicine. Inter-medicine Department, P31-33.

15-Melchiors A., Pontarolo R., \& Correr C., (2010): Quality of Life in Hypertensive Patients and Concurrent Validity of Minichal-Brazil, Vol 94, No 3, p 337-344.

16-Mostafa M., (2017): Study of hypertensive patient in outpatient clinics in sohag university hospital, Faculty of medicine- internal medicine Department, P 4-67.

17-Naing M., Nanthamongkolchai S., \& Munsawaengsub C., (2015): Quality of Life of the Elderly People in Einme Township Irrawaddy Division, Myanmar, Asia Journal of Public Health, Vol 1, No 2, p 4-10.

18-Prior J., Jordan K., \& Kadam U., (2012): Influence of chronic diseases on long-term change in physical health: a consultation-survey linkage cohort study in general practice, Springer Science Business Media, Quality Life Res (2012), Vol 21, P 581-591.

19-Sonntage A., Bischkop F., Ritz A., Jakob A., \& Angermeyer C., (2013): Wishes of Nursing Home Residents Concerning Their Life SituationResults of a Qualitative Study . Z Gerontol Geriatr; 36 (4): 280-6.

20-World Health Organization (WHO) (2018): Measuring the global population of older persons in worldwide. World report on ageing and healthy ageing, pp.25, 28. 